\title{
OS KAINGANG DO PARANÁ E SEUS DESLOCAMIENTOS CÍCLICOS PARA O MATO GROSSO DO SUL
}

\author{
KimiyeTommasino*
}

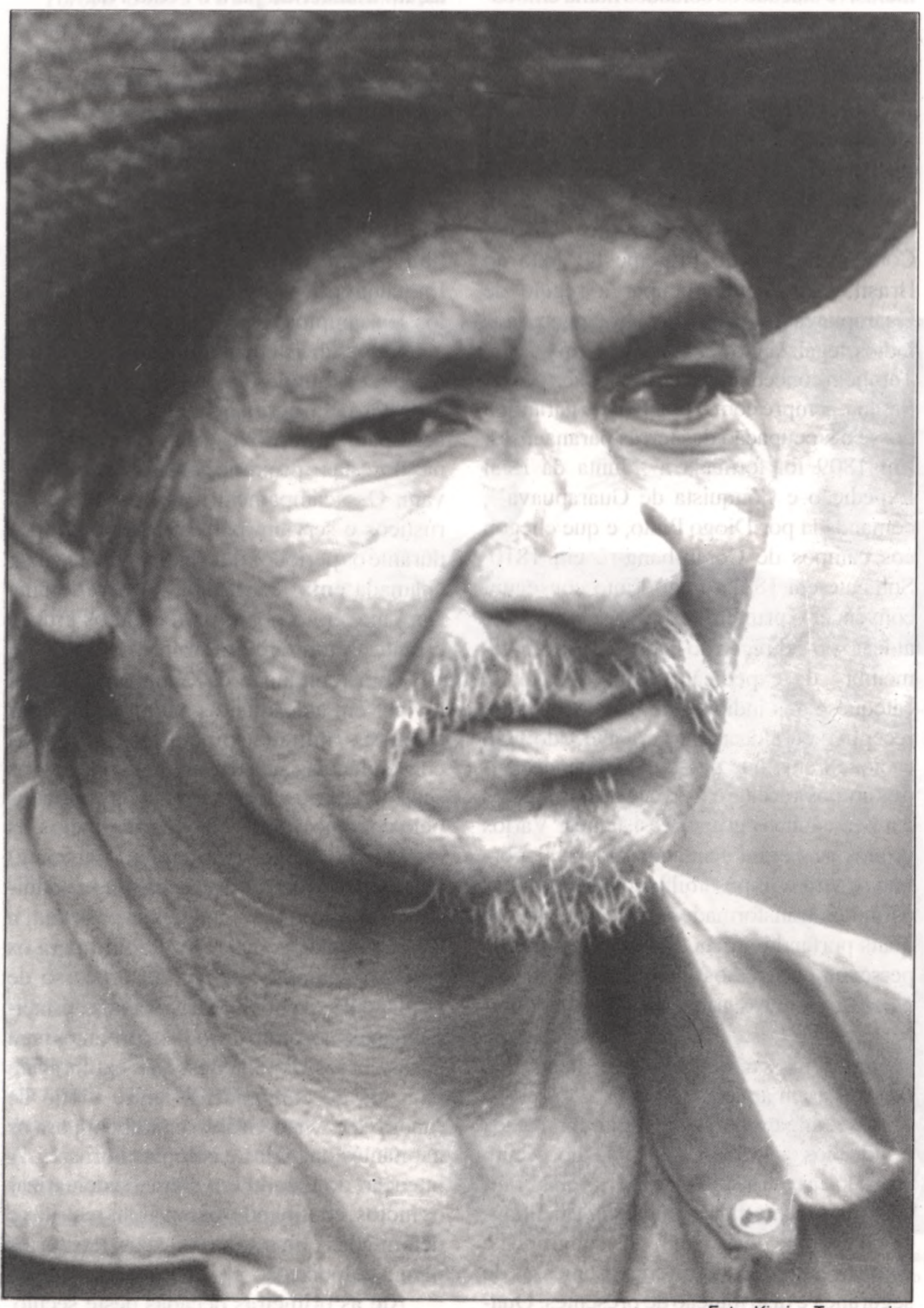

Foto: Kimiye Tommasino
$\mathbf{F}$ ste artigo refere-se a uma sociedade Jê meridional e à experiência recente de alguns de seus membros como trabalhadores temporários no município de Brasilândia-MS. Os Kaingáng dos Postos Indígenas Apucarana (municipio de Londrina), Barão de Antonina e São Jerônimo (municipio de São Jerônimo da Serra), localizados na região norte do Estado do Paraná, começaram a se deslocar para a Fazenda da Destilaria Brasilândia S/ADEBRASA há cerca de cinco anos, onde vãocortarcana-de-açúcar. Permanecem por periodos de 60 dias e repetem essas viagens três a quatro vezes ao ano.

Os Kaingáng pertencem ao tronco linguístico Jê e vivem hoje nas reservas indigenas dos Estados de São Paulo, Paraná, Santa Catarina e Rio Grande do Sul. No total são cerca de 20 mil pessoas. No Paraná vivem pouco mais de oito mil, distribuídos $\mathrm{em} 11$ postos indígenas. Nossa pesquisa refere-se aos Kaingáng de três postos que se localizam na região norte do Estado do Paraná: Postos Indígenas Apucarana (municipio de Londrina), Barão de Antonina e São Jerônimo (município de São Jerônimo da Serra).

\section{Antecedentes Históricos}

O território que hoje constitui o Estado do Paraná abrigava povos indigenas de vários grupos étnicos. Os Cários ou Carijó, que habitavam a costa atlântica no século XVI, foram exterminados ou levados como escravos para o Rio de Janeiro e São Vicente e desapareceram ainda no período colonial. No século XVII, os jesuitas espanhóis obtêm autorização de D. Felipe e instalam dezenas de reduções que abrigavam principalmente índios Guarani, mas também foi registrada a presença de Gualachos e Guayanás. As reduções foram fundadas às margens dos rios Paranapanema, Pirapó, 
Piquiri, Tibagi e Ivaí, confirmando a presença de muitos grupos indigenas distribuidos em todo oterritório do que é hoje o Estadodo Paraná. As reduções foram: Nossa Senhora do Loreto, Santo Inácio, São José, São Francisco Xavier, Encarnação, São Miguel, São Tomás, Los Angeles, São Paulo, Conceição, Jesus Maria, São Pedro e Santa Maria.

Os bandeirantes paulistas encontraram nessas reduções um celeiro de índios que buscavam para escravizar e vender no mercado de São Vicente. Mas, além do interesse pela preação de indios, o governo lusobrasileiro temia a expansão espanhola para o leste, ao mesmo tempo que intencionava estender o limite do Brasil meridional para o oeste e sul, mais especificamente o rio da Prata. Expedições dos bandeirantes Raposo Tavares e Manoel Preto destruíram as reduções e levaram milhares de índios escravizados para São Paulo. Os que conseguiram fugir com os missionários se fixaram mais ao sul, às margens do rio Uruguai e fundaram outras reduções, inclusive no território que se tornou o Rio Grande do Sul. (Wachovics, 88:25/37). Apesar de os historiadores afirmarem que toda a região daquelas reduções ficou completamente abandonada, muitos grupos certamente permaneceram vivendo nas matas e campos, retornando à vida como povos livres.

Por outro lado, com as investidas dos luso-brasileiros, os Kaingáng que viviam mais próximos do litoral atlântico, de Angra dos Reis e Cananéia, começaram a se deslocar em direção ao oeste, interiorizando-se para evitar o confronto com os brancos. Pelas informações dos viajantes do século XVIII e XIX, os Kaingáng aparecem no Paraná ocupando regiões às margens dos rios Iguaçu, Santo Antonio, Chopim, sul do rioUruguai eregião de Guaíra, no rioParaná. (Elliot, 1847; Wachovics, 1987; 1988; Tempski, 1986).

\section{A Conquista dos Territórios Kaingáng no Paraná}

Entre 1768 e 1774 o governo português empreendeu um projeto de reconhecimento, posse e ocupação das terras a oeste do meridiano das Tordesilhas, reconhecidas como pertencentes aos portugueses pelo Tratado de Madrid em 1750. Dezenas de expedições foram enviadas para o interior com esta intenção. Ocorre que tais terras estavam ocupadas por grupos indigenas e a posse necessariamente passava pela conquista dos mesmos. A primeira expedição, chefiada por Cândido Xavier, chegou em 1770 aos Campos de Coran-bang-rê, conhecidos na historiografia como campos de Guarapuava. No mesmo ano uma outra expedição, comandada por Francisco Martins Lustosa, partiu em direção ao mesmo local, lá chegando em 1771. Apesar da simpatia de alguns Kaingáng, vários grupos rejeitaramo contato e principalmente o convite para se aldearem sob a direção dos brancos, tendo inclusive atacado os soldados numa emboscada. Vendo que não estava em condições de vencer as forças indigenas, Cândido Xavier preferiu retirar-se.

Apesar do tratado de Santo Ildefonso ter reconhecido a posse portuguesa do território paranaense, as outras expedições não tiveram sucesso na efetivação da ocupação, tal a resistência dos Kaingáng e Xokléng. Com a chegada do Príncipe D. João ao Brasil, este decidiu ocupar a região de Guarapuava e para isso declarou guerra aos índios, legalizando a sua caça e escravização. Também concedeu sesmarias nos sertões do Paraná, sempre com o objetivo de garantir a posse e a ocupação das terras paranaenses. Em 1809 foi formada a "Junta da Real Expedição e Conquista de Guarapuava", comandada por Diogo Pinto, e que chegou aos campos de Coran-bang-rê em 1810. Somente em 1812 Diogo Pinto conseguiu convencer o primeiro grupo Kaingáng a se aldear sob a direção do padre Chagas Lima, membro da expedição e encarregado da catequese dos indios. Tal grupo Kaingáng receptivo ao aldeamento era chefiado pelo cacique Pahy, que passou a convencer outros grupos a aceitarem viverem aldeamentos e a perseguir os grupos resistentes. Vários grupos acabaram aceitando aldear-se porque se viram impossibilitados de enfrentar os índios transformados em bugreiros, os quais portando armas de fogo, passaram a perseguir os arredios através das chamadas correrias. Outros grupos preferiram migrar para o sul e lá se estabeleceram até serem atingidos, mais tarde, pelas expedições que conquistaram aquelas terras.

Os Kaingáng do Tibagi foram contatados e aldeados a partir da metade do século passadoe as estratégias utilizadas pelos brancos foram as mesmas: conquistar a confiança do cacique de cada um dos subgrupos e convencê-los a se aldear com promessas de segurança e distribuição de presentes. Qua- se todos os grupos do Tibagi se aldearam ainda no século passado, mas no início deste século, com o abandono por parte do governo republicano, boa parte retornou à vida livre nas florestas. Em 1930 os últimos grupos arredios foram pacificados pelo Serviço de Proteção aos Índios-SPI e pela Companhia de Terras Norte do Paraná-CTNP. Viviam nas florestas entre o rio Cinzas e Laranjinha e um grupo de 42 indios ficou aldeado no Posto Laranjinha, até morrerem nas epidemias que grassaram nos anos $30 \mathrm{e}$ 40. Um outro grupo, de cerca de 100 pessoas, foi transferido para o Posto Ivaí.

\section{A Falência do Indigenismo e as Alternativas de Sobrevivência}

Odeslocamento geográficodos Kaingáng não é estranho aos seus costumes nem constitui fenômeno recente em sua vivência. Enquanto povos livres, perambulavam pelos seus amplos territórios de caça, pesca e coleta. A subsistência implicava a exploração de seus amplos territórios, que se caracterizava pela permanência temporária em acampamentos provisórios que construíam nas florestas e próximo aos rios, onde pescavam. Os acampamentos provisórios eram rústicos e serviam para abrigar os grupos durante os períodos de estadia. A aldeia fixa, chamada emã, construida no alto de uma campina, era o ponto para onde os grupos errantes sempre retornavam.

Com a conquista, os Kaingáng passaram a viver em aldeamentos administrados por diretores militares ou religiosos. Várias consequências sucederam de lá para cá: os seus territórios foram sendo apropriados pelo governo e pelos colonos não-índios; as populações indígenas (Guarani e Kaingáng) passaram a viver em áreas restritas e definidas pelo governo; os indigenas passaram a ser recrutados como mão-de-obra para os diversos trabalhos dentro do processo de implantação da nova ordem social e, principalmente, passaram a produzir produtos para abastecer as expedições que exploravam uma via de comunicação entre o Rio de Janeiro e o Mato Grosso e também para os habitantes das vilas e colônias militares. A intenção do Estado era clara: sedentarizar os índios, confinando-os em áreas restritas e delimitadas, liberando os seus territórios para a colonização.

Até as primeiras décadas deste século, 
os Kaingáng ainda puderam sobreviver da caça e coleta porque as florestas ainda dominavam praticamente todoo EstadodoParaná. Mas os índios passaram a conviver com a presença de núcleos de neonacionais, e a vida $\mathrm{em}$ aldeamentos foi sendo modificada à medida $\mathrm{em}$ que se intensificava a expansão da colonização conhecida nas ciências sociais como frente pioneira, iniciada nos anos 30. Os anos 50 representam para os índios uma ruptura com a relativa liberdade que ainda gozavam: o governo do Estado e a União celebraram um acordo em 1949 que expropriou cerca de $90 \%$ das terras reservadas aos indios, com a finalidade explicita de ampliar terras para acolher os novos colonos nacionais e estrangeiros. Se atéos anos 50 as florestas das áreas reservadas aos índios permaneceram intactas, nas décadas de $60 \mathrm{e}$ 70 o próprio SPI montou serrarias nos postos indigenas para beneficiar a madeira das terras sob sua jurisdição. Pode-se dizer que o próprio indigenismo foi um dos agentes da devastação e destruição do habitat indígena. Depoimentos de velhos Kaingáng revelam que vários chefes de posto praticavam atos ilegais na exploração de madeira de áreas indigenas.

Nesse processo, os recursos florestais de caça e coleta também desapareceram e os Kaingáng viram aumentar a dependência tanto da estrutura indigenista quanto do mercado regional, que passaram a constituir as novas fontes de subsistência. O assalariamento e outras formas de subordinação econômica foram se tornando predominantes em relação ao modo de vida livre enquanto caçadores-coletores. A caça e a pesca, quando são praticadas hoje, têm um caráter mais lúdicoe acontecem nos fins-desemana, mas estão presentes na memória coletiva como atividades de subsistência centrais da sociedade. A coleta, excetuandose o palmito, desapareceu.

No final dos anos 70, a Fundação Nacional do Índio-FUNAI, considerando os índios das reservas do sul como "aculturados", formulou uma politica para que desenvolvessem projetos agrícolas modernos $\mathrm{e}$ integrados ao mercado regional, nacional e internacional. Surgiram assim projetos de criação de bicho-da-seda e fábrica de roupas no Posto Araribá, além de grandes projetos de soja e trigo no Rio Grande do Sul e Santa Catarina.

No Paraná, além das chamadas "roças coletivas", a FUNAI introduziu plantações financiadas e administradas por agrônomos e técnicos agrícolas da instituição com a utilização de mão-de-obra indigena. Essa economia administrada, onde a instituição tutelar aparece como um "empresário moderno", tem como critério de seleção os produtos voltados para o mercado, mais especificamente o algodão, o milho (híbrido) e o arroz. As roças de subsistência familiares passaram a ocupar um lugar secundário na política do órgão tutelar.

As chamadas "roças coletivas" resultam em fracassos. Os motivos são vários: a FUNAI, ao se tornar empregador dos índios, só paga diárias durante uma parte do processo produtivo e depois suspende o pagamento, entregando a cada trabalhador indigena a responsabilidade por uma parte da roça. Nesta fase, a maioria dos indios abandona as roças porque não há remuneração. Além disso a FUNAI arregimenta os índios de acordo com o padrão branco, isto é, individualmente, contrariando o costume dos indios Kaingáng que ainda hoje desenvolvem suas atividades de subsistência seguindo o padrão tradicional, ou seja, organizando-se em grupos de parentesco: quando fazem suas roças, quando acampam em Londrina para vender seu artesanato, quando vão pescar. Pode-se dizer que todas as atividades são formas de junção dos indivíduos ligados pelo parentesco. Ora, as roças administradas pela FUNAI seguem um padrão estranho aos índios e em vez de junção, promovem a disjunção. Acresce-se ainda um terceiro fator: as comunidades Kaingáng estão divididas em grupos que se antagonizam por diferenças internas e que não se juntariam num mesmo projeto. Se um grupo adere ao projeto da FUNAI, o outro, necessariamente, fica fora. Somando toda essa complexidade, a burocracia e a falta de recursos acabam levando, com raríssimas exceções, ao fracasso dos projetos oficiais.

\section{O Assalariameto da Mão-de-obra indigena no Paraná}

Desde o século passado as expedições de reconhecimento, caça aos índios e outras finalidades, feitas pelo branco, contavam constantemente com alguns índios retirados das comunidades, as quais, contudo, continuavam mantendo seu modo de vida tradicional. Com a destruição das matas e a expropriação da maior parte de suas terras, entre os anos 30 e 60 , de forma a impedir a subsistência baseada na caça-coleta-agri- cultura, é que o assalariamento geral dos homens Kaingáng vai modificar radicalmente o padrão tradicional, inserindo os índios no sistema de mercado regional e nacional.

A pesquisa de Cecilia Maria V. Helm nos anos 70 já os evidencia vivendo na condição de assalariados, arrendatários e meeiros, portanto praticando uma nova forma de deslocamento, ou seja, para fora da reserva, tornando-se empregados explorados pelos sitiantes e fazendeiros. Muitas famílias Kaingáng passaram a viver fora da reserva, fixando-se em terras arrendadas ou lá permanecendo no periodo das empreitadas. Esse fato revela que a produção das roças das reservas era insuficiente para garantir a auto-suficiência das familias. Helm também mostrou as formas autoritárias do indigenismo no interior das reservas do Paraná. Por outro lado, na década de 70 , o Paraná passou por profundas alterações na estrutura fundiária e nas relações de trabalho no campo. A consequência foi a expulsão da zona rural, tanto das famílias indigenas quanto dos trabalhadores rurais nacionais. Os Kaingáng que estavam desaldeados acabaram retornando para as reservas e as familias dos trabalhadores nacionais foram habitar as periferias das cidades ou migraram para as novas áreas de colonização.

Para os Kaingáng o assalariamento continuou sendo a alternativa predominante de sobrevivência, mas agora sob novas condições: apenas os homens passaram a se deslocar temporariamente para os locais de trabalho. Essa passou a constituir a forma predominante de deslocamento e permanência dos trabalhadores indígenas até os dias atuais

A crise econômica que vem se agudizando no Brasil nas últimas décadas tem afetado praticamente toda a população brasileira, mas seu reflexo nas áreas indígenas é alarmante. A FUNAI está praticamente falida e os seus recursos não permitem custear sequer a própria estrutura indigenista. $\mathrm{O}$ abandono das famílias indigenas é total e os projetos de "desenvolvimento" implantados peloórgão, além de não levar em conta a especificidade sócio-econômico-cultural dos índios e seus interesses, não contam com recursos do governo federal. A subnutrição, a fome, as doenças são lugar-comum em todas as reservas do sul do pais.

Sem poder contar com recursos da FUNAI, os Kaingáng passaram a buscar formas alternativas e complementares para a sobrevivência. Os Kaingáng do Posto 
Apucarana combinam as roças de subsistência com o assalariamento dos homens e o comércio de artesanato das mulheres que constituem as formas que permitem alguma renda para suprir a pauta das necessidades ampliadas pela experiência de contato. Os de São Jerônimo da Serra combinam as roças familiares com o assalariamento externo. Como vimos, o assalariamento externo já é antigo mas nos últimos anos ocorre uma novidade: em 1990, os indios começaram a ser recrutados pela Usina DEBRASA queencontrou namão-de-obra indigenauma fonte segura de exploração. Além dos Kaingáng dos Postos Apucarana, Barão de Antonina e São Jerônimo, contratam indios do Estado do Mato Grosso, Terena e Kayoá. São contratados para o corte da cana-deaçúcar. Nas épocas de pico, segundo os próprios trabalhadores Kaingáng, são cerca de dois mil índios cortando cana.

\section{As reservas indigenas como celeiro de mão-de-obra barata}

Para a Usina DEBRASA, a descoberta das reservas indigenas pode ser considerada como um ovo de Colombo. Todos sabem que o recrutamento dos trabalhadores volantes em determinadas épocas não é uma tarefa fácil para os empregadores e seus intermediários. Além dos trabalhadores brancos estarem dispersos na periferia de váriascidades, os mesmoscontam com apoio de entidades civis e religiosas e possuem um grau razoável de consciência dos seus direitos trabalhistas. Os indios, ao contrário, vêm ao longo deste século sendo explorados pelo próprio indigenismoe pelos fazendeiros que, aproveitando-se de sua condição de tuteladose de pertencerem a uma outra cultura, os mantiveram, com algumas exceções, à margem do conhecimento das regras do mercado e das leis que protegem os trabalhadores. As pesquisas de Helm $(1974 ; 1978)$ revelam que os Kaingáng do Paraná trabalhavam para os fazendeiros recebendo menos que os trabalhadores nacionais que faziam o mesmo serviço. A pesquisadora mostrou que os empregadores brancos, quando se tratava de empregar mão-de-obra indigena, justificavam a superexploração argumentando com o próprio preconceito e invertendo a relação, isto é, interpretando o fato de estar empregando um indigena como sendo um ato de favor. A nossa pesquisa, que vem sendo realizada desde 1988 , confirma a ple- na vigência desta superexploração.

\section{As viagens dos Kaingáng para o Mato Grosso do Sul}

A partir de 1990, os Kaingáng passaram a viajar para o Mato Grosso do Sul, distante cerca de $400 \mathrm{Km}$ de Londrina, e têm ido regularmente até quatro vezes ao ano. As condições de alojamento são degradantes, conforme denunciou um jornalista de Londrina que esteve visitando os indios na Usina e foram confirmadas por alguns deputados $\mathrm{e}$ pela Comissão do Ministério do Trabalho que autuou e multou a empresa por irregularidades. A jornada de trabalho, segundo os depoimentos dos próprios índios, é dura, intensa e perigosa.

Mesmo depois de multada, a empresa continuou mandando os ônibus para virem apanhar os índios nas reservas. Alguns índios se tornaram os próprios "cabeçantes" (chefe responsável de turma) e recebem uma comissão da Usina. Quando a imprensa veiculou matéria denunciando as condições subumanas de vida e de superexploração, a FUNAI enviou uma comissão do órgão formada por um advogado, um técnico agricola e uma assistente social, os quais concluiram que as condições não eram tão ruins e ainda culparam os próprios indios pelas más condições do alojamento. $\mathrm{O}$ administrador e o advogado da FUNAI de Londrina declararam que o jornalista teria exagerado sobre as péssimas condições a que se sujeitavam os indios e justificaram que, como a FUNAI não tinha recursos para manter as famílias dentro das reservas, tinha de "fazer vistas grossas",

Em 1994, um trabalhador Kaingáng do Posto A pucarana morreu esmagado por uma máquina agricola na Usina DEBRASA, e no primeiro semestre de 1995 mais um jovem do Posto São Jerônimo morreu vítima de acidente de trabalho. Recentemente o Conselho Indigena do Paraná, que vinha assumindo a mediação entre a Usina e as comunidades Kaingáng, decidiu que os índios não retornarão para o Mato Grosso. Ocorre que as condições de vida das familias Kaingáng continuam as mesmas, isto é, muito ruins, e a FUNAI continua cada vez com menos recursos. Isso nos leva a acreditar que, mesmo não desejando, os índios poderão ver-se na situação de terem de retornar à Usina. Recente depoimento de um Kaingán afirma que hoje são sete usinas no Mato Grosso do Sul que contratam mão-de-obra indigena.
Para completar o quadro de análise, percebemos que, para os Kaingáng, as viagens para o Mato Grosso do Sul constituem-se como uma verdadeira excursão dos homens rumo a uma terra distante repleta de perigos onde têm de provar coragem e resistência física e moral. As próprias mulheres que ficam nas reservas e têm seus filhos e maridos na Usina observaram que a saída e a chegada dos homens acabou se constituindo em uma verdadeira "festa" Oretorno, principalmente, é barulhento e festivo: soltam rojões quando estão chegando, "para avisar a turma". A nossa interpretaçãoé que houve uma impregnação dessas viagens com o sentido das excursões tradicionais quando faziam guerra ou iam caçar. É como se hoje tivessem de arriscar a vida e cumprir alguns meses de privações longe de casa para retornarem como "homens valentes". E isso, em nosso entendimento, acaba favorecendo oexplorador branco. Trata-se de mais um paradoxo da própria história produzido pelo contato entre índios e brancos.

As nossas conclusões sobre as migrações que os Kaingáng vêm desenvolvendo desde que foram conquistados nos revelam a trajetória de milhares de populações autóctones que viviam na América e cujas histórias foram capturadas pelo processo civilizatório e dele não podem se libertar. Perderam a terra, e com ela, a liberdade de que gozavam. Se as migrações de seus ancestrais livres expressavam um modo de vida que lhes permitia viver com autarcia $\mathrm{e}$ produzir/reproduzir uma sociedade baseada numa economia de floresta auto-sustentada, cujo binômio Homem/Natureza garantia a preservação de seus recursos materiais c sociais, hoje os Kaingáng são grupos marginalizados no interior de uma sociedade mais ampla, cuja lógica destrói tanto o Homem quanto a Natureza.

\section{* Kimiye Tommasino é Professora adjunta do De- partamento de Ciências Sociais da Universidade Estadual de Londrina; Doutora pela Universidade de São Paulo.}

\section{BIBLIOGRAFIA}

- HELM, M.C.V. A Integração do Indio na Estrutura Agrária do Paraná. Tese de livre-docência, UFPR. Curitiba, 1974.

O Indio Camponés Assalariado em Londrina. Relações de Trabalho e Identidade Étnica. Mimeo., 1978.

- Relatório da Comissão FUNAI - Administração Regional de Londrina. Londrina, 16 de agosto de 1993.

- Jornal Folha de Londrina, 02/05/93; 10/10/93; 12/10/ 93; 22/10/93. 